NASA Technical Memorandum 82625

\title{
Environmental Effects on Graphite Fiber Reinforced PMR-15 Polyimide
}

\section{LIBRARY COPY}

Tito T. Serafini and Morgan P. Hanson Lewis Research Center

Cleveland, Ohio

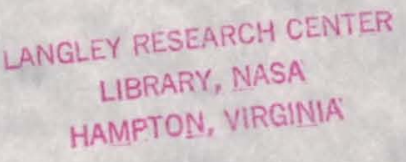

Prepared for the

Symposium "Composites for Extreme Environments" sponsored by the American Society for Testing and Materials Bal Harbor, Florida, November 11-12, 1980 
ENVIRONMENTAL EFFECTS ON GRAPHITE

FIBER REINFORCED PMR-15 POLYIMIDE

by

Tito T. Serafini and Morgan P. Hanson

National Aeronautics and Space Administration

Lewis Research Center

Cleveland, Ohio

INTRODUCTION

Fiber reinforced polymer matrix composites, particularly those based on epoxies, are achieving considerable acceptance as engineering materials for the fabrication of aerospace structural components. However, the maximum use temperature of fiber reinforced epoxies is limited to about $177^{\circ} \mathrm{C}$. Until the development of PMR polyimides (Ref. 1), attempts to increase the use temperature of fiber reinforced composites by utilizing high temperature resistant polymers as matrix materials invariably met with little success. The commercial availability of prepreg materials based on the PMR polyimide, designated as PMR-15, has now made it possible to design and fabricate fiber reinforced polymer matrix composites for use at temperatures up to $316^{\circ} \mathrm{C}$, or nearly twice the use temperature of epoxy based composites.

The effects of long term exposure in air at elevated temperatures (thermooxidative exposure) and the combined effects of absorbed moisture and elevated temperatures (hydrothermal exposure) on composite properties are two areas of vital concern to the designers of composite structures. Many studies have been performed to determine the effects of thermo-oxidative exposure on the properties of PMR-15 reinforced with continuous graphite fibers. In contrast, studies to determine the effects of thermo-oxidative exposure on the

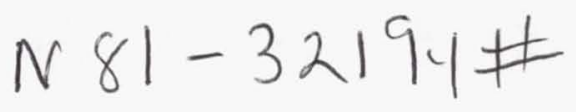


properties of graphite fabric reinforced PMR-15 composites have not been reported. The area of hydrothermal effects on PMR-15 composites has not been extensively studied. Although the effects of hydrothermal exposure on the properties of PMR-15 reinforced with continuous Celion 6000 graphite fibers have been investigated (Ref. 2), the effects of hydrothermal exposure on T300 graphite fabric reinforced PMR-15 have not been reported.

The purpose of this investigation was to determine the effects of thermooxidative and hydrothermal environments on the properties of T300 graphite fabric/PMR-15 composites. The effects of hydrothermal exposure on the properties of HTS-2 continuous graphite fiber composites were also determined. The effects of the thermo-oxidative and hydrothermal environments on composite properties were established on the basis of changes to the room temperature and elevated temperature composite flexural strengths and moduli and interlaminar shear strengths after environmental exposure. The thermooxidative stability characteristics of T300 graphite fabric and T300 graphite fabric/PMR-15 composites were also determined.

\section{EXPERIMENTAL PROCEDURE}

\section{Materials}

Style 182 fabric woven from Union Carbide T300 graphite fibers and Hercules HTS-2 graphite fiber tows were used as reinforcing materials. The T300 fibers consisted of 3000 filaments in a one-ply construction and were sized with an epoxy compatible sizing. The HTS-2 fibers consisted of 12,000 filaments per tow. 
The polyimide resin used in this investigation was the high temperature polyimide designated as PMR-15. The monomers used to formulate PMR-15 are shown in Table 1. The monomethyl ester of 5-norbornene-2,3-dicarboxylic acid (NE) and 4,4'-methylenedianiline (MDA) were obtained from commercial sources. The dimethyl ester of 3,3', 4,4'-benzophenonetetracarboxylic acid (BTDE) was prepared as a 50 weight percent solution by refluxing a suspension of the corresponding dianhydride in annydrous methanol for approximately 2.75 hours. The monomer stoichiometry for the PMR-15 solution was 2NE/3.087MDA/2.087BTDE. The PMR-15 solution was prepared by dissolving the monomers in a calculated amount of anhydrous methanol to yield a 50 weight percent solution.

\section{Composite Fabrication and Specimen Preparation}

To prepare the unidirectional fiber prepreg tape, the HTS-2 tows were wound on a drum at approximately 3 turns per centimeter and impregnated with a predetermined quantity of resin to provide cured laminates having a fiber content of 55 to 60 volume percent. The prepregs were air dried to reduce the solvent content to approximately 10 percent prior to removal from the drum. HTS-2 laminates having a thickness of $0.20 \mathrm{~cm}$ were prepared by cutting $7.6 \mathrm{X}$ $20.3 \mathrm{~cm}$ plies from the prepreg tape and unidirectionally stacking ten plies between porous Armalon fabric in a preforming mold. The stacked lay-up was imidized at $204^{\circ} \mathrm{C}$ for one hour under a pressure of approximately $0.07 \mathrm{~N} / \mathrm{cm}^{2}$. Compression molding was accomplished by placing the preform into a matched metal die that had been preheated to $232^{\circ} \mathrm{C}$. Following a dwell 
time of 5 minutes at essentially zero pressure, a mold pressure of $345 \mathrm{~N} / \mathrm{cm}^{2}$ was applied and the mold temperature was increased to $288^{\circ} \mathrm{C}$ at the rate of $5.6^{\circ} \mathrm{C}$ per minute. Pressure and temperature were maintained for two hours followed by cooling to $204^{\circ} \mathrm{C}$ before releasing the pressure and removing the laminate from the die. The cured laminates were postcured in an air circulating oven in which the temperature was raised from ambient temperature to $288^{\circ} \mathrm{C}$ at a rate of $2.2^{\circ} \mathrm{C}$ per minute and held at $288^{\circ} \mathrm{C}$ for 16 hours.

The T300 graphite fabric/PMR-15 prepreg was obtained from a commercial source with a resin content of approximately 40 percent by weight. Laminates having thicknesses of 0.14 and $0.28 \mathrm{~cm}$ were fabricated using the same procedure that was employed for the unidirectional HTS-2/PMR-15 1aminates. A11 plies for the fabric laminates were stacked with their warp yarns in the $0^{\circ}$ direction.

\section{Composite Environmental Exposure}

Coupons (approximately one-third of a $7.6 \times 20.3 \mathrm{~cm}$ laminate) were subjected to either thermo-oxidative or hydrothermal exposure. All of the coupons were cut from essentially void free laminates as assessed by uitrasonic C-scan. The thermo-oxidative environments were provided by air circulating ovens. Bleed air was metered into the ovens at a rate of 100 $\mathrm{cm}^{3}$ per minute. Coupons were periodically removed from the ovens and allowed to cool to room temperature in a desiccator before reweighing to determine weight losses. The hydrothermal environment was accomplished by 
supporting the laminate coupons in a closed chamber above a water bath held at $82^{\circ} \mathrm{C}$ so that condensate formed on the laminate surfaces. The coupons were periodically removed from the cnamber, blotted dry and then weighed. After saturation had been attained (no significant increase in coupon weight with increased exposure time) the coupons were removed from the chamber and sealed in a vapor proof container. The conditioned coupons were cut into flexural and short beam shear specimens using a diamond cutting blade. Flexural specimens were $1.27 \mathrm{~cm}$ wide by $6.67 \mathrm{~cm}$ long. The short beam shear specimens were $0.64 \mathrm{~cm}$ wide; the lengths of the specimens were selected so as to result in a shear test span-to-thickness ratio of 4 .

\section{Composite Testing}

Flexural tests conformed essentially to the ASTM standard method D790. Tests were made on a 3-point loading fixture with a variable span. Tests were performed using a span-to-thickness ratio of approximately 32 . The rate of center loading for flexural testing was $0.127 \mathrm{~cm}$ per minute. Interlaminar shear strength tests were conducted in accordance to ASTM D2344 using a constant span-to-thickness ratio of 4 . For the elevated temperature tests, the load was applied to the specimens after the chamber had equilibrated at the test temperature for 10 minutes. A limited number of temperature spike tests were performed on moisture saturated specimens. For these tests, the load was applied to the specimen immediately after the specimen was installed in the preheated test fixture. 


\section{RESULTS AND DISCUSSION}

Fiber and Composite Thermo-0xidative Stability

Figure 1 shows the weight loss characteristics of T300 and HTS-2 graphite fibers after isothermal exposure in air at $316^{\circ} \mathrm{C}$. The data for the HTS-2 fibers were taken from reference 3 . The superior thermo-oxidative stability of the HTS-2 fibers is clearly evident. After 800 hours of exposure in air at $316^{\circ} \mathrm{C}$, the weight loss of the HTS-2 fibers was only 4.2 percent compared to the 50 percent weight loss exhibited by the T300 fibers after 500 hours in air at $316^{\circ} \mathrm{C}$. The comparatively poor elevated temperature thermo-oxidative stability of T300 fibers would very likely be manifested in inferior composite performance at temperatures approaching $316^{\circ} \mathrm{C}$.

The weight loss behavior of T300 graphite fabric/PMR-15 composites as a function of exposure time is shown in figure 2 for composites exposed in air at $260^{\circ}, 288^{\circ}$, and $316^{\circ} \mathrm{C}$. In contrast to the behavior of the bare unprotected T300 fibers which exhibited a weight loss of 50 percent after 500 hours of exposure at $316^{\circ} \mathrm{C}$, the weight loss of the T300/PMR-15 composites was on 1 y 4.8 percent after 500 hours at $316^{\circ} \mathrm{C}$. The significant increase in the rate of composite weight loss after about 400 hours at $316^{\circ} \mathrm{C}$ is clearly evident. Similar weight loss behavior has not been previously reported for graphite fiber reinforced PMR-15 composites exposed at $316^{\circ} \mathrm{C}$. The significantly increased weight loss rate found in this study for the T300/ PMR-15 composites is undoubtedly due to the limited thermo-oxidative stability of the T300 fibers at $316^{\circ} \mathrm{C}$. As expected, the T300/PMR-15 composites 
exhibited improved oxidative stability at $260^{\circ} \mathrm{C}$ and $288^{\circ} \mathrm{C}$. After 1000 hours at $288^{\circ} \mathrm{C}$ and 500 hours at $260^{\circ} \mathrm{C}$, the composite weight losses were only 4.2 and 0.8 percent, respectively. The results of these composite weight loss studies indicate that the useful life of T300/PMR-15 composites at $316^{\circ} \mathrm{C}$ is likely less than 400 hours and is at least 1000 hours at $260^{\circ}$ and $288^{\circ} \mathrm{C}$.

Figure 3 shows the flexural and interlaminar shear properties retention characteristics of $0.14 \mathrm{~cm}$ thick laminates and the flexural properties retention characteristics of $0.28 \mathrm{~cm}$ thick laminates. Specimens of both thicknesses were exposed at $316^{\circ} \mathrm{C}$ for various time intervals and then tested at $288^{\circ} \mathrm{C}$. It can be seen that during exposure at $316^{\circ} \mathrm{C}$, the $288^{\circ} \mathrm{C}$ flexural strengths and moduli of both laminate thicknesses decreased rapidly whereas the interlaminar shear strength of the $0.14 \mathrm{~cm}$ thick laminate decreased more gradually. After 620 hours of exposure at $316^{\circ} \mathrm{C}$, the flexural strength and modulus retention values for the $0.14 \mathrm{~cm}$ thick laminates were 33 and 40 percent, respectively, compared to a retention value of 78 percent for interlaminar shear strength. In view of the limited oxidative stability of the T300 fibers and T300/PMR-15 composites at $316^{\circ} \mathrm{C}$, the rapid degradation of flexural properties was not unexpected. However, it was difficult to account for the large difference between the retention values for the flexural and interlaminar shear properties only on the basis of surface degradation. To ascertain if the difference might have resulted from structural features that were present in the as-fabricated composites or were introduced during elevated temperature exposure, cross-sections of as-fabricated and exposed specimens were examined metallographically. 
Figure 4 shows representative photomicrographs of specimens from $0.14 \mathrm{~cm}$ thick T300 graphite fabric/PMR-15 as-fabricated laminates and from laminates that had been exposed at $316^{\circ} \mathrm{C}$. Figure 4 a shows that the as-fabricated laminates were defect free. In figure $4 b$, it can be seen that a few through-the-surface-ply cracks had developed after 120 hours of exposure. Figure $4 c$ shows that after 624 hours of exposure, the cracks were more numerous. As is known, specimens subjected to flexural testing fail at one of the surfaces by either a tensile or compressive failure mode whereas shear specimens fail at the neutral plane of the specimen. Hence, it appears that surface cracking as well as surface degradation (weight loss) are responsible for the large difference between flexural and shear properties. More importantly, it appears that the overall degradation which occurs at $316^{\circ} \mathrm{C}$ limits the useful lifetime of T300/PMR-15 composites at $316^{\circ} \mathrm{C}$ to about 100 hours.

Figure 5 shows the flexural and shear properties retention characteristics for $0.14 \mathrm{~cm}$ thick laminates that were exposed and tested at $288^{\circ} \mathrm{C}$. As expected, the composites exhibited improved properties retention characteristics after exposure at $288^{\circ} \mathrm{C}$ than after exposure at $316^{\circ} \mathrm{C}$. For example, the flexural and interlaminar shear strength retention values were 75 and 96 percent, respectively, after 500 hours at $288^{\circ} \mathrm{C}$ compared to retention values of 46 and 88 percent for the same properties after 500 hours at $316{ }^{\circ} \mathrm{C}$. Figure 6 shows photomicrographs of laminate cross-sections after exposure at $288^{\circ} \mathrm{C}$ for 500 and 1000 hours. It can be seen in figure $6 \mathrm{a}$ that only a limited number of through-the-surface cracks had developed after 500 
hours of exposure at $288^{\circ} \mathrm{C}$. Figure $6 \mathrm{~b}$ shows that the surface cracking had become extensive after 1000 hours exposure. Based on the results of the $288^{\circ} \mathrm{C}$ exposure studies, it may be concluded that the useful lifetime of T300/PMR-15 composites at $288^{\circ} \mathrm{C}$ is 1 imited to about 500 hours.

Figure 7 shows the mechanical properties retention of 0.14 and $0.28 \mathrm{~cm}$ thick T300/PMR-15 composites that were exposed at $260^{\circ} \mathrm{C}$ and tested at $288^{\circ} \mathrm{C}$. After 1000 hours of exposure at $260^{\circ} \mathrm{C}$, both laminate thicknesses exhibited properties retention levels of 90 percent or more. The significant increase in the flexural strength of the $0.14 \mathrm{~cm}$ laminates as the exposure time increased to 500 hours cannot be explained. The important point to note is that the T300/PMR-15 composites exhibited excellent retention of properties after 1000 hours of exposure at $260^{\circ} \mathrm{C}$. Figure 8 shows that laminates that had been subjected to extended exposure at $260^{\circ} \mathrm{C}$ were almost completely free of any surface cracks. Thus, it may be concluded that the useful lifetime of T300/PMR-15 composites at $260^{\circ} \mathrm{C}$ is at least 1000 hours.

\section{Hydrothermal Characteristics}

As is known, the absorption of moisture by polymer matrix composites adversely affects the strength and elastic properties of the composites at elevated temperatures. It has been shown that the reduction in elevated temperature properties is caused by the plasticizing effect of moisture on the matrix reducing its glass transition temperature, or $\mathrm{Tg}$ (Ref. 4). In this study, unidirectional graphite fiber (HTS-2) and graphite fabric (T300) 
reinforced PMR-15 composites were exposed to moisture until saturation had been achieved. To assess the effect of moisture on laminate properties, the flexural strengths, moduli, and interlaminar shear strengths of the saturated materials were determined at various temperatures.

Figure 9 shows a comparison of the properties of moisture saturated (wet) HTS-2/PMR-15 laminates having a thickness of $0.20 \mathrm{~cm}$ to baseline properties (no moisture exposure) as a function of test temperature. The wet flexural strengths and moduli were only slightly lower than the baseline properties up to $204^{\circ} \mathrm{C}$. However, at $260^{\circ}$ and $316^{\circ} \mathrm{C}$, the wet flexural strengths and moduli were 10 to 20 percent lower than the baseline properties. The wet interlaminar shear strengths of the laminates were 10 to 18 percent lower than the baseline properties at all test temperatures.

Figure 9 also points out some of the uncertainties associated with determining realistic properties of wet laminates at elevated temperatures. The words "realistic properties" refer to properties of the wet laminates with minimal desorption of moisture during elevated temperature testing. Data, indicated by the tailed symbols, are shown in figure 9 for the flexural strengths and moduli of wet specimens that were subjected to a temperature spike. As described earlier in the experimental procedure section of this report, in a temperature spike test, the load was applied to the specimen immediately after it had been installed in the heated test fixture. Temperature measurements have shown that the temperature of the test specimen approaches the test fixture temperature before the specimen fails. Figure 9 shows that the flexural strengths and moduli of the temperature spiked wet 
specimens are significantly lower than the flexural properties of wet

specimens that were equilibrated at the test temperature for 10 minutes prior to applying the load. These results clearly show that the absorption of moisture by PMR-15 composites is reversible. The lower flexural properties of the temperature spiked specimens undoubtedly reflect the Tg lowering effect of moisture on the PMR-15 matrix. The Tg of a temperature spiked moisture saturated unreinforced epoxy resin was found to be approximately $100^{\circ} \mathrm{C} 10$ wer than its $\mathrm{Tg}$ in the dry condition (Ref. 4). A corresponding reduction in the $\mathrm{Tg}$ of moisture saturated PMR-15 could lower the Tg of fiber reinforced PMR-15 composites from $336^{\circ} \mathrm{C}$ in the dry state (Ref. 5) to perhaps $236^{\circ} \mathrm{C}$. Thus, the much greater reduction in flexural properties of temperature spiked specimens, especially at the higher test temperatures (e.g., reductions of 49 and 25 percent, respectively for flexural strength and modulus at $316^{\circ} \mathrm{C}$ compared to reductions of 12 and 6 percent for the same properties at $204^{\circ} \mathrm{C}$ ) indicate that in the temperature spike tests, the specimens were tested above or near the Tg of wet HTS-2/PMR-15 composites. In contrast to the behavior found for flexural properties, no discernible differences were observed between the interlaminar shear strengths of temperature spiked specimens and temperature equilibrated specimens. A possible explanation for the contrasting behavior is as follows. It is well known that the exposure of a laminate plate to moisture establishes a moisture gradient through the laminate thickness. Also, as was discussed in the "Fiber and Composites Thermo-oxidative Stability" section of this report, shear failure of an interlaminar shear specimen occurs at the neutral, or mid-plane of the 
specimen. It is possible that the moisture concentration at the neutral plane was not altered by subjecting the specimen to either the 10 minute equilibration period or to the temperature spike, hence, wet specimens tested in either manner failed at the same load. It should also be recalled that failure of a flexural specimen occurs at one of its surfaces. Apparently, during temperature spike testing of flexural specimens the moisture concentration of the surface plies remained at a higher level than the moisture concentrations of the surface plies of specimens which had been equilibrated for 10 minutes at elevated temperature. The higher moisture concentration in the surface plies of temperature spiked specimens would have caused them to undergo compressive failures at lower loads than was observed for specimens which had been equilibrated at the elevated temperatures prior to loading.

Figure 10 compares the properties of wet $0.14 \mathrm{~cm}$ thick T300 fabric reinforced PMR-15 laminates with baseline properties as a function of test temperature. Because the trends observed for this composite system are similar to those observed for wet HTS-2/PMR-15 laminates tested at elevated temperatures, the points discussed for wet HTS-2/PMR-15 are also pertinent to T300/PMR-15 and accordingly will not be repeated.

In summary, the results of this study on the effects of hydrothermal exposure on the properties of graphite fiber reinforced PMR-15 composites indicate that absorbed moisture causes a reduction of $\mathrm{Tg}$ which is reflected in lower properties at elevated temperatures. It needs to be noted, however, that the absorption of moisture is reversible. 


\section{CONCLUSIONS}

Based on the results obtained in this investigation, the following conclusions can be drawn:

1. The useful lifetimes of T300 graphite fabric reinforced PMR-15 composites

exposed in air at $316^{\circ}$ and $288^{\circ} \mathrm{C}$ are approximately 100 and 500 hours, respectively. The useful lifetime in air at $260^{\circ} \mathrm{C}$ is at least 1000 hours.

2. Absorbed moisture reduces the elevated temperature properties of graphite fiber reinforced PMR-15 composites.

3. Temperature spike testing of moisture saturated composites provides a more realistic assessment of the effect of absorbed moisture on the elevated temperature properties of composites.

4. The absorption of moisture by graphite fiber reinforced PMR-15 composites is reversible. 
1. Serafini, T. T., Delvigs, P., and Ligntsey, L. R., Journal of Applied Polymer Science, Vol. 16, 1972, pp. 905-915.

2. Davis, J. G., Jr., in Selected NASA Research in Composite Materials and Structures, NASA CP-2142, National Aeronautics and Space Administration, Washington, D.C., 1980, pp. 143-782.

3. Velvigs, P., Alston, W. B., and Vannucci, R. D., "Effects of Graphite Fiber Stability on the Properties of PMR Polyimide Composites," NASA TM-79062 and AVRADCOM-TR-78-62, National Aeronautics and Space Administration, Washington, D.C., 1979.

4. Browning, C. E., "The Mechanisms of Elevated Temperature Property Losses in Hign Performance Structural Epoxy Resin Matrix Materials After Exposure to High Humidity Environments," AFML-TR-76-153, Air Force Materials Laboratory, Wright-Patterson AFB, OH, Mar. 1977.

5. Serafini, T. T. and Delvigs, P., Proceedings of the 1978 International Conference on Composite Materials, B. Noton, Ed., American Institute of Mining, Metallurgical and Petroleum Engineers, Inc., New York, 1978, pp. 1320-132y. 
TABLE 1 - MONOMERS USED FOR PMR 15 POLYIMIDE

\begin{tabular}{|c|c|c|}
\hline STRUCTURE & NAME & ABBREVIATION \\
\hline & $\begin{array}{l}\text { MONOMETHYL ESTER OF 5-NORBORNENE- } \\
\text { 2,3-DICARBOXYLIC ACID }\end{array}$ & NE. \\
\hline & & \\
\hline
\end{tabular}

CS -71803

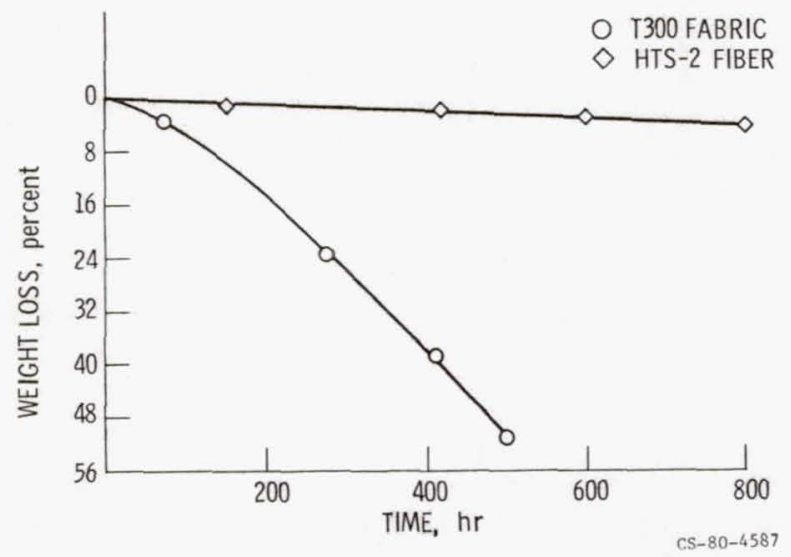

Figure 1. - Weight loss of graphite fibers exposed in air at $316^{\circ} \mathrm{C}$. 


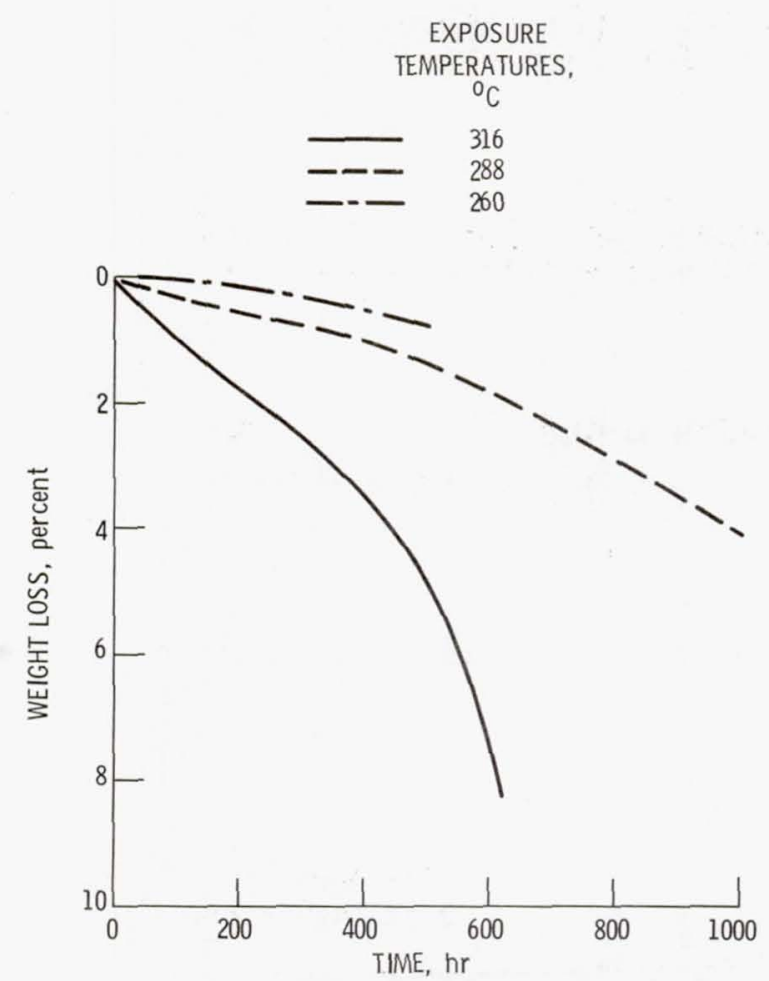

Figure 2. - Weight loss of T300 graphite fabric/PMR-15 composites exposed at elevated temperatures.
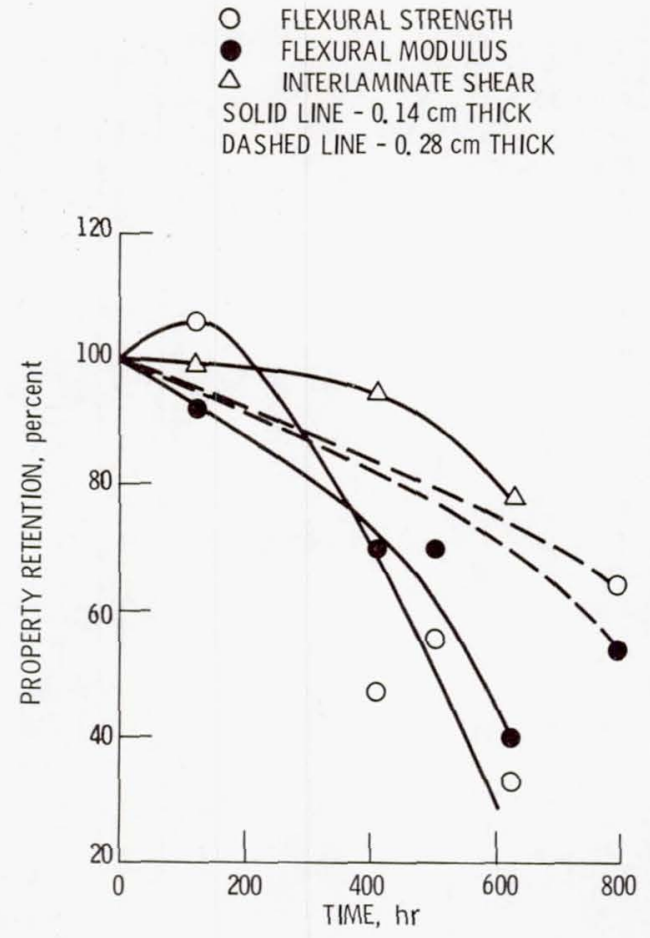

Figure 3. - Property retention of $\mathrm{T} 300$ graphite fabric/PMR- 15 composites exposed at $316^{\circ} \mathrm{C}$ and tested at $288^{\circ} \mathrm{C}$. 


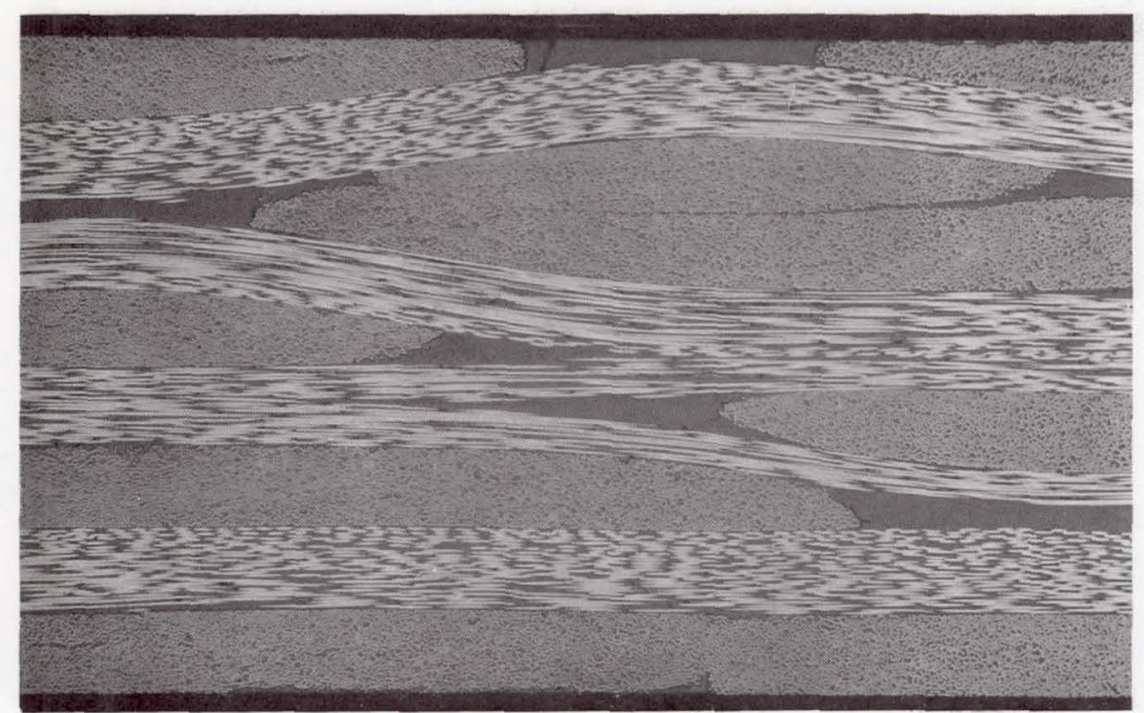

(a) AS FABRICATED.

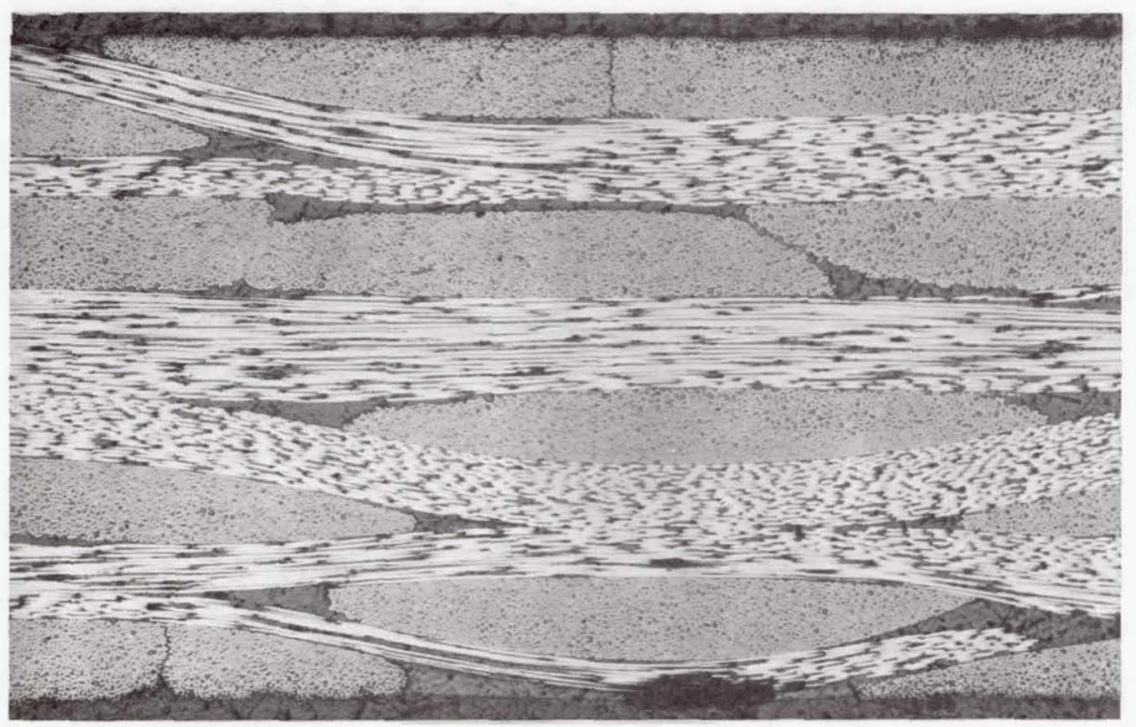

(b) $120 \mathrm{hr}$ AT $316^{\circ} \mathrm{C}$.

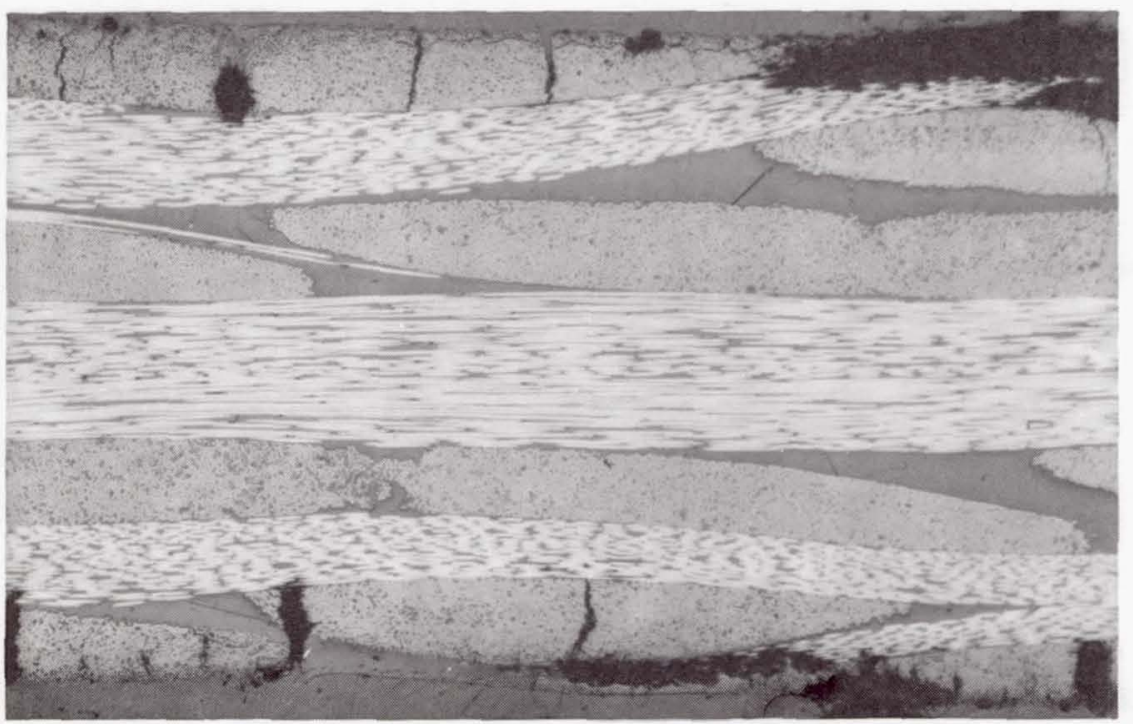

(c) $624 \mathrm{hr}$ AT $316^{\circ} \mathrm{C}$.

Figure 4. - Typical photomicrographs of $T 300$ graphite fabric/PMR-15 composites after various thermal-oxidative exposures. $\times 50$. 
O FLEXURAL STRENGTH

- flexural modulus

$\triangle$ INTERLAMINAR SHEAR

$0.14 \mathrm{~cm}$ THICK

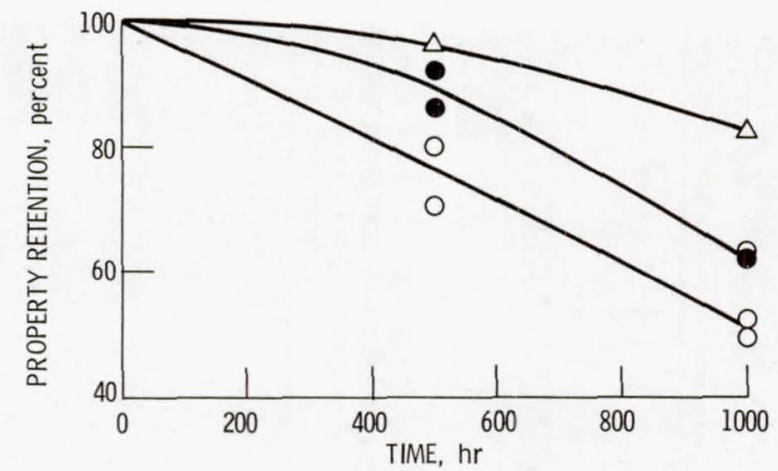

Figure 5. - Property retention of T300 graphite fabric/PMR-15 composites exposed at $288^{\circ} \mathrm{C}$ and tested at $288^{\circ} \mathrm{C}$. 


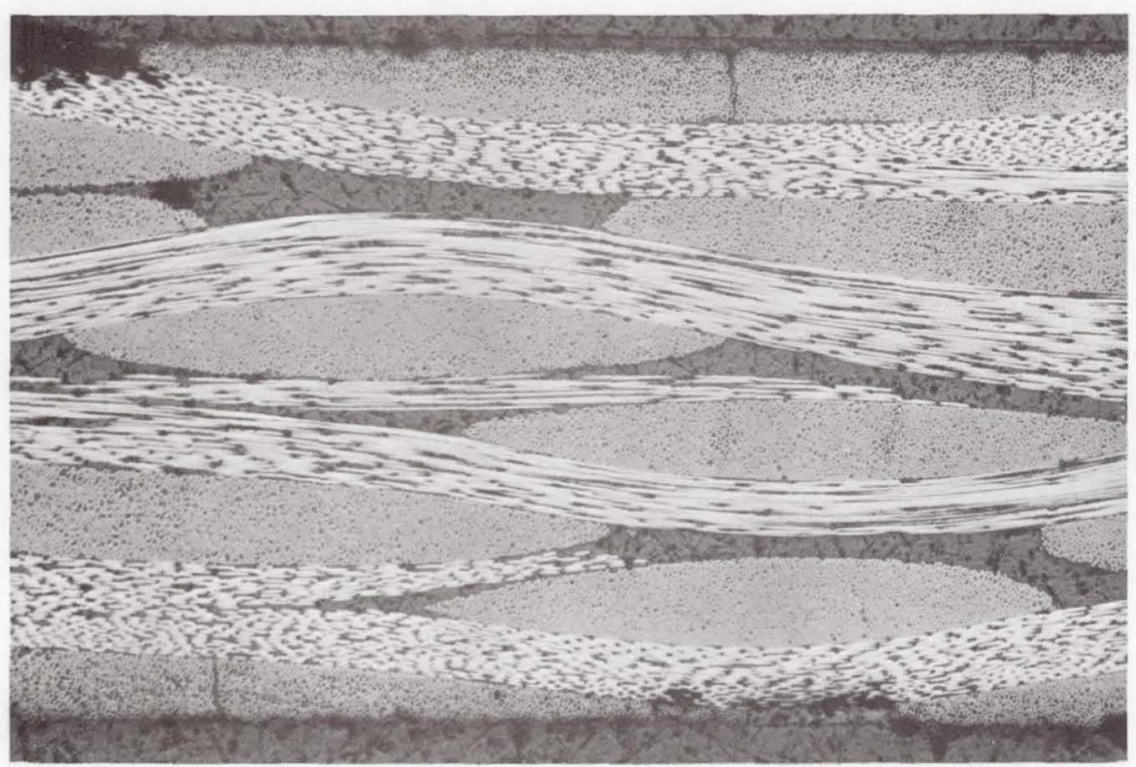

(a) 500 hr AT $288^{\circ} \mathrm{C}$

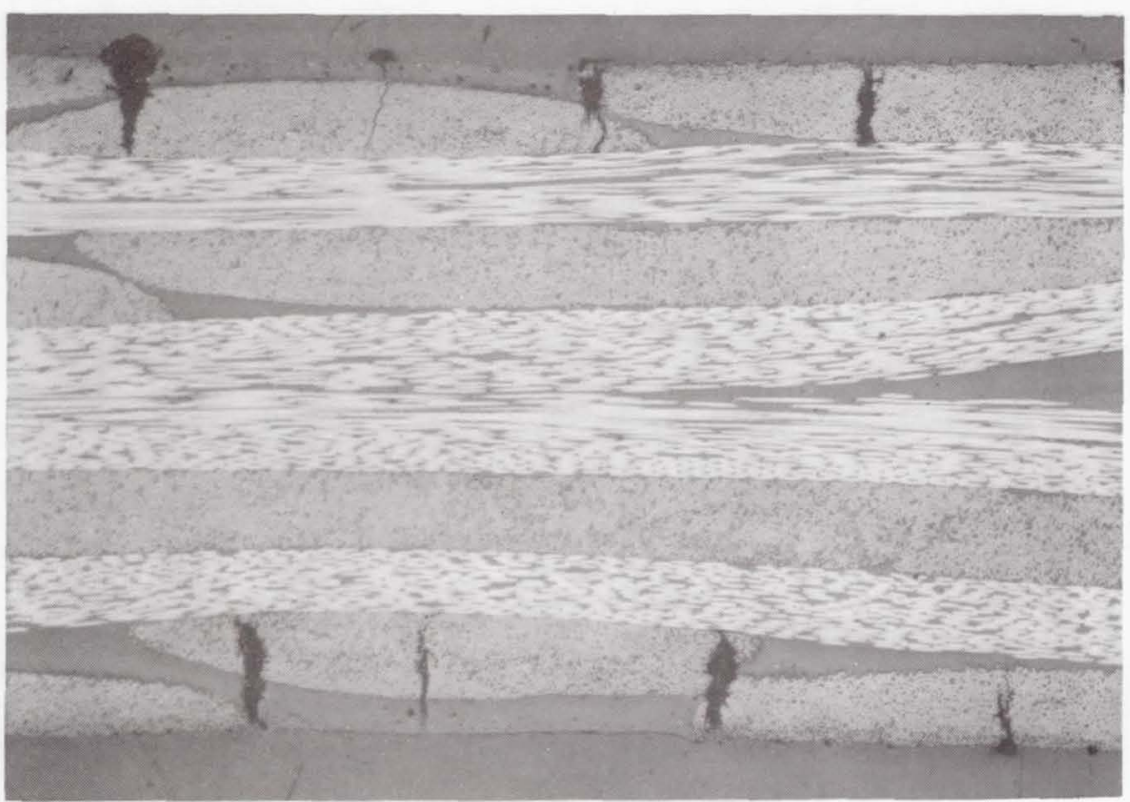

(b) $1000 \mathrm{hr}$ AT $288^{\circ} \mathrm{C}$.

Figure 6. - Typical photomicrographs of $T 300$ graphite fabric/PMR- 15 composites after various thermal-oxidative exposures. $\times 50$. 


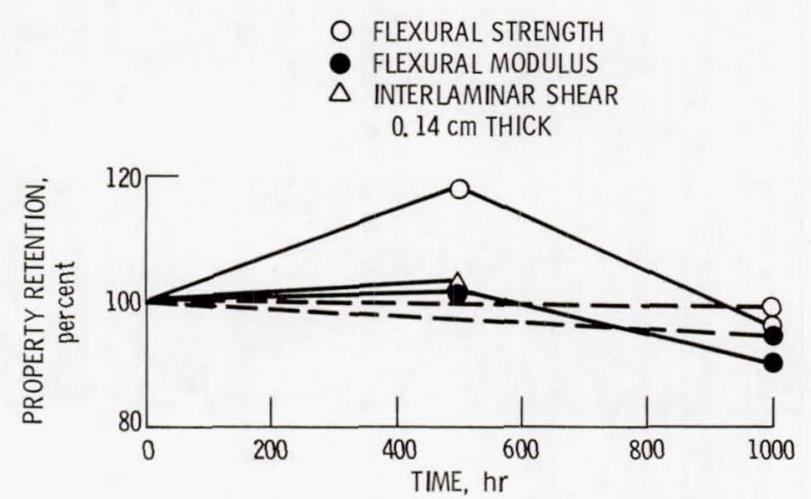

Figure 7. - Property retention of T300 graphite fabric/PMR-15 composites exposed at $260^{\circ} \mathrm{C}$ and tested at $288^{\circ} \mathrm{C}$ 


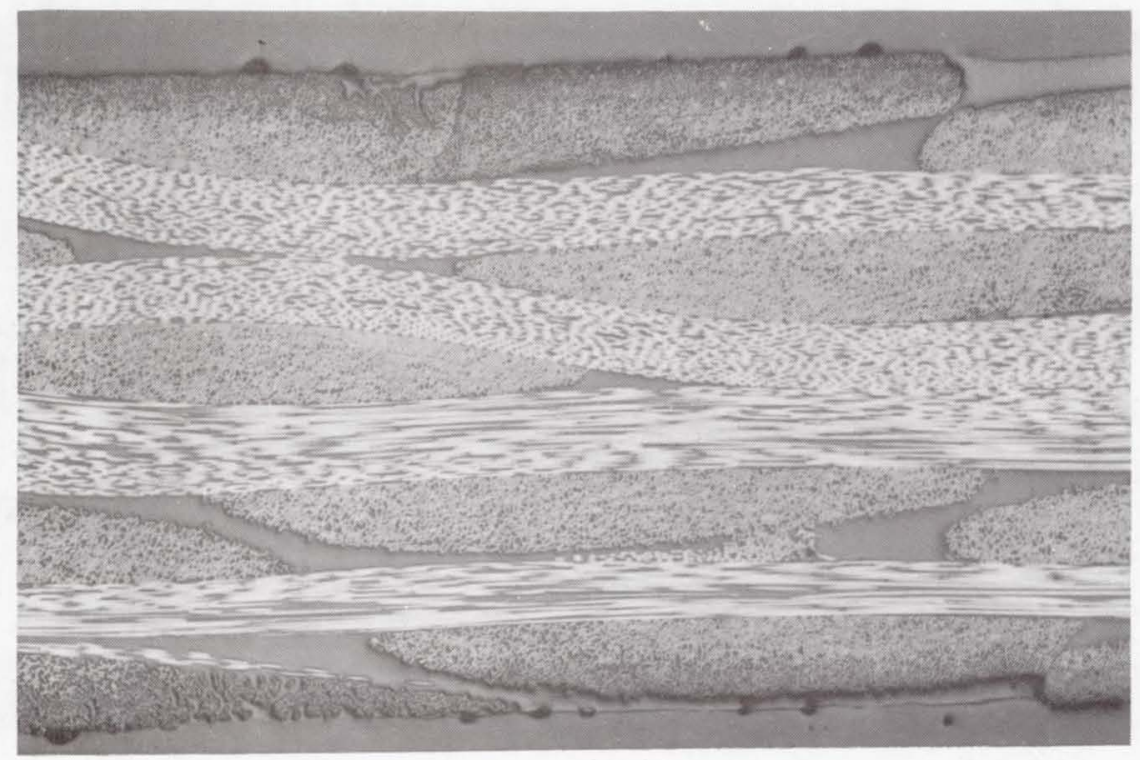

(a) $500 \mathrm{hr}$ AT $260^{\circ} \mathrm{C}$.

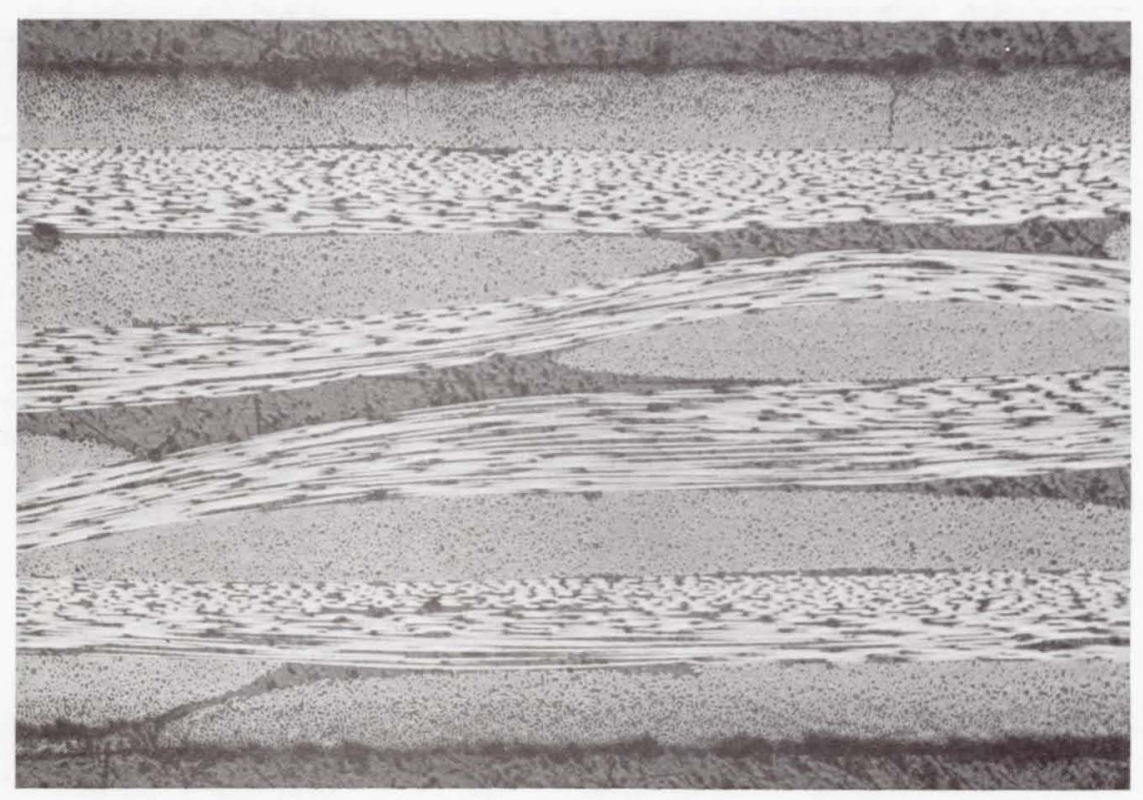

(b) $1000 \mathrm{hr}$ AT $260^{\circ} \mathrm{C}$.

Figure 8. - Typical photomicrographs of T300 graphite fabric/PMR- 15 composites after various thermal-oxidative exposures. $\times 50$. 

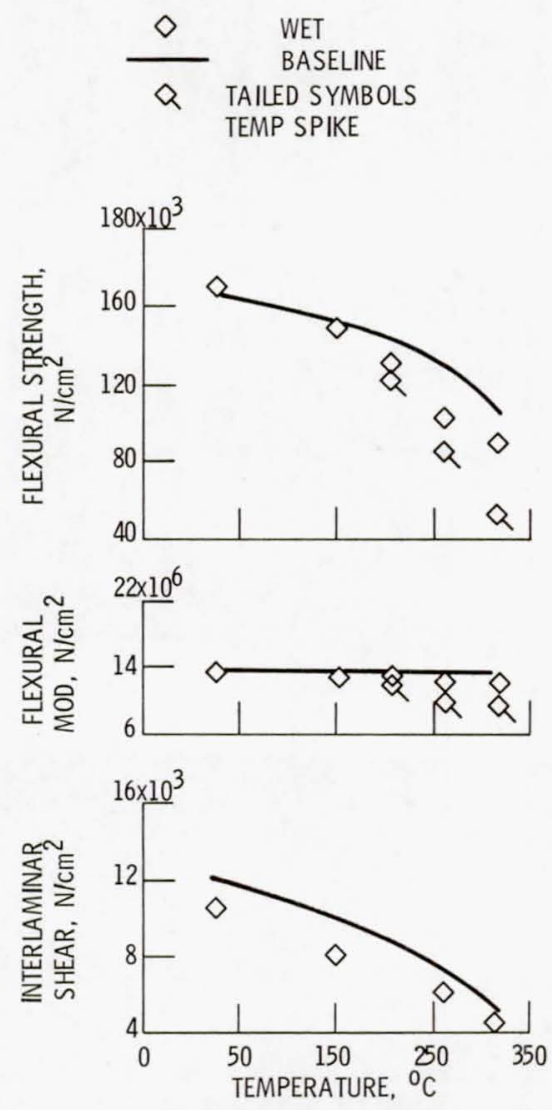

Figure 9. - Comparison of hydrothermally exposed HTS/PMR-15 composite properties to baseline properties.
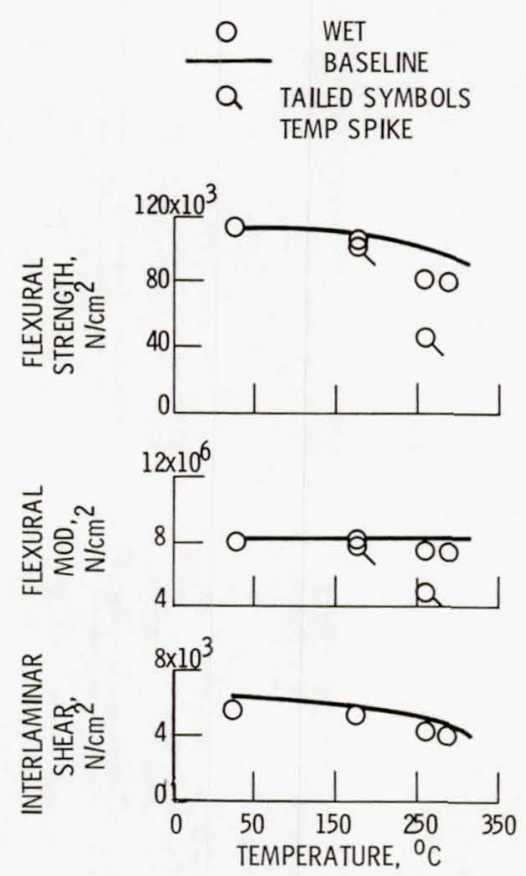

Figure 10, - Comparison of hydrothermally exposed $\mathrm{T} 300$ fabricl PMR-15 composite properties to baseline properties. 


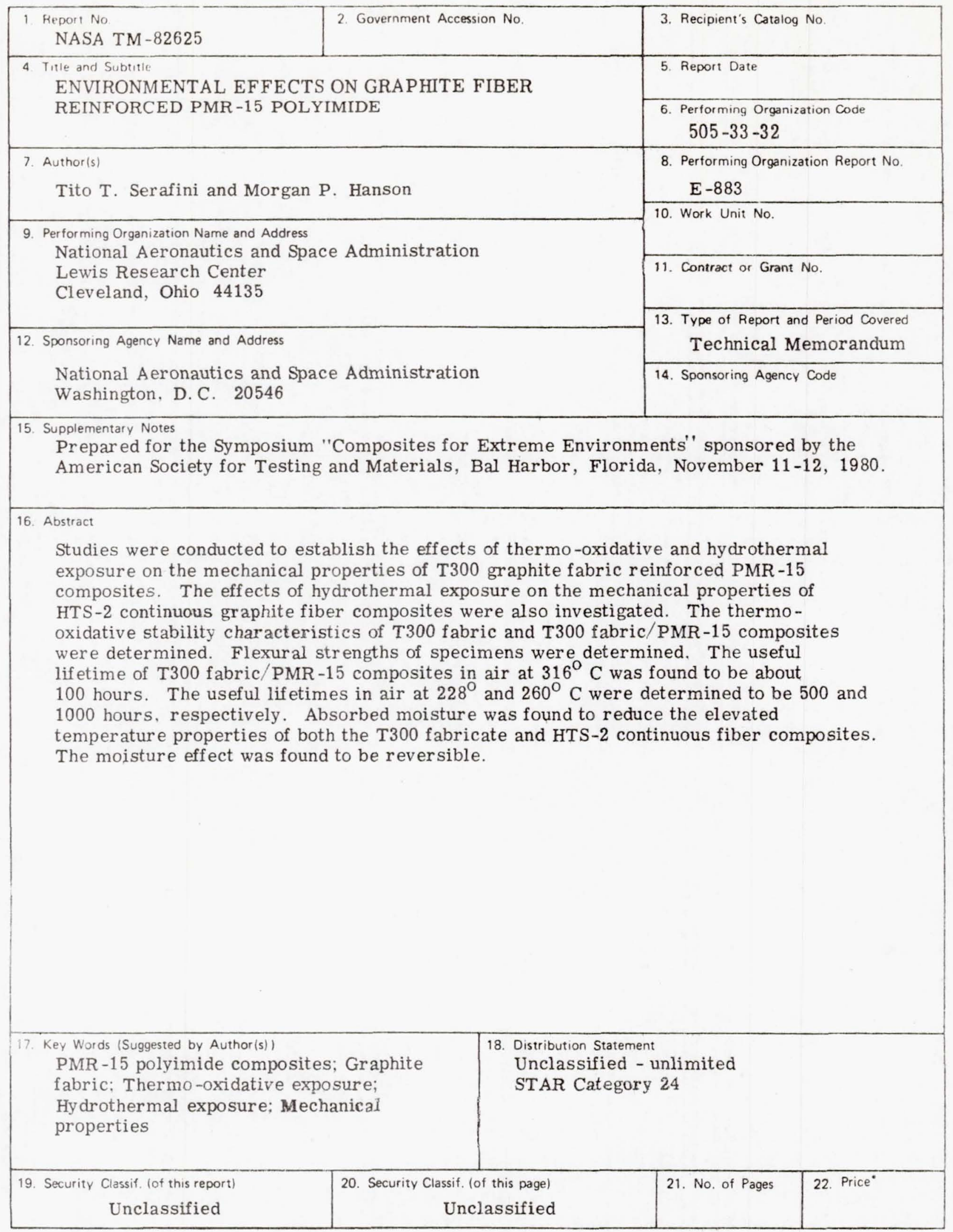

*For sale by the National Technical Information Service, Springfield. Virginia 22161 
National Aeronautics and Space Administration

Washington, D.C.

20546

Official Business

Panalty for Private Use, $\$ 300$
SPECIAL FOURTH CLASS MAIL

BOOK

Postage and Fees Paid

3. National Aeronautics and Space Addministration NASA-451

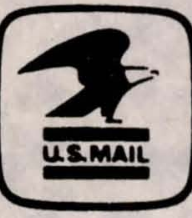

